Gut, 1978, 19, 865-869

\title{
Comparison of an intragastric method of estimating acid output with the pentagastrin test in normal and duodenal ulcer subjects
}

\author{
T. V. TAYLOR, J. B. ELDER ${ }^{1}$, P.C. GANGULI, AND I.E. GILLESPIE \\ From the University Department of Surgery, Manchester Royal Infirmary, Manchester
}

SUMmARY Using Fordtran's technique but substituting the meat extract Oxo for the steak meal we investigated gastric acid secretion in eight control subjects and nine patients with chronic duodenal ulcer. Intragastric titration was performed using a double lumen tube measuring the $\mathrm{pH}$ in the stomach every three minutes and adjusting it to $5 \cdot 5$ throughout the test by infusing $0 \cdot 3-\mathrm{M}$ sodium bicarbonate. On a separate day a pentagastrin test was performed using a conventional gastric aspiration technique. In the eight control subjects the mean acid output after pentagastrin was $13 \cdot 7 \pm 2 \cdot 1(\mathrm{SEM}) \mathrm{mmol} / \mathrm{h}$, whereas the mean hourly acid output measured by intragastric titration was $20 \cdot 1 \pm 3 \cdot 1$. The greater response to Oxo than to pentagastrin in the controls $(\triangle \mathrm{AO}=+46 \%)$ was significant $(\mathrm{P}<0.01)$. This is in contrast with our duodenal ulcer patients whose mean hourly acid outputs were $22.7 \pm 4.4$ and $23.0 \pm 4.4 \mathrm{mmol} / \mathrm{h}$ in response to pentagastrin and Oxo respectively $(r=0.95)$. The findings, while clearly at variance with those of Fordtran and Walsh (1973), are more in keeping with the concept of increased endogenous secretory drive in duodenal ulcer patients compared to normal subjects.

It has always been difficult to measure the rate of acid secretion when food has been present in the human stomach, and almost all our physiological information on the response of the stomach to food has been obtained in laboratory animals with gastric pouches used to mirror the performance of the main stomach. Rune (1966) estimated acid output in response to a solid meal, but this technique required arterial puncture in order to measure changes in arterial base. Fordtran and Walsh (1973) recently suggested a method for measuring gastric acid secretion in the presence of food in the human stomach. These workers assessed the acid secretory response to a meal consisting of steak and bread and butter by intragastric titration with sodium bicarbonate. Malagelada and his colleagues (1976) used a much more refined technique with both gastric and duodenal markers to measure gastric secretory responses without artificially maintaining the $\mathrm{pH}$ of the stomach at $5 \cdot 5$-thus avoiding the

\footnotetext{
${ }^{1}$ Address for reprint requests: Mr J. B. Elder, Department of Surgery, The Royal Infirmary, Manchester, M13 9WL.
}

Received for publication 18 May 1978 possibility of substantially altering perhaps both gastric acid secretion and serum gastrin levels.

The meat extract Oxo (Brooke Bond Oxo, Limited) is well known to be a potent stimulant of gastrin release from the antrum (Giles and Clark, 1966) and, using a much simpler protocol than Malagelada et al., we routinely use it in our laboratory to determine the integrated plasma gastrin response'.

In this study our aim has been to compare an intragastric titration method of estimating acid output, using Oxo stimulation, with the conventional pentagastrin stimulation test in normal and duodenal ulcer patients.

\section{Methods}

Eight control volunteer subjects with normal intact stomachs and nine preoperative patients with chronic duodenal ulceration were studied. Four standard Oxo cubes were dissolved in $400 \mathrm{ml}$ of water at $37^{\circ} \mathrm{C}$., giving a $6.25 \%$ w.v. solution. The mean $\mathrm{pH}$ of five solutions made up in this way was $5 \cdot 4$, with a range of $5 \cdot 2-5 \cdot 5$. To reduce the $\mathrm{pH}$ of the solution to $3 \cdot 0,26 \mathrm{mmol} \mathrm{HC} 1$ were required, and to 
reduce it to $2 \cdot 0,44 \mathrm{mmol}$. Allowing the solution to stand overnight made no difference to this titration, and adding the equivalent amount of sodium bicarbonate at all stages brought the $\mathrm{pH}$ back to its original value. Duplicate titrations of several samples of the Oxo solution were performed on several occasions noting the amounts of $0 \cdot 1 \mathrm{MHCI}$ required to reduce the $\mathrm{pH}$ to 4,3 , and 2 . We found that $r=0.99$ for $\mathrm{T} 1$ versus $\mathrm{T} 2(\mathrm{n}=12, \mathrm{y}=0.99 \times$ +0.064 ).

After an overnight fast each subject was intubated with a double lumen nasogastric tube (Anderson no. AN 10). The distance between the proximal and distal openings on the tube was $10 \mathrm{~cm}$. A $2 \mathrm{ml}$ sample of fasting gastric juice was aspirated, the $\mathrm{pH}$ measured, and then it was returned to the stomach. Usually the $\mathrm{pH}$ was below 5.5 and $0.3 \mathrm{M}$ sodium bicarbonate was infused from a Braun Unita pump through the fine limb of the tube until the intragastric $\mathrm{pH}$ was adjusted to 5.5. Essentially the technique was that of Fordtran and Walsh (1973).

Four hundred millilitres of Oxo were introduced through the longer limb of the nasogastric tube, corresponding to the distal opening, using a $50 \mathrm{ml}$ syringe. With the subject resting in the recumbent position the gastric content was sampled at three minute intervals for one hour. To facilitate adequate mixing the subject was asked to rotate from side to side and the left hypochondrium was compressed gently and intermittently. Fifty millilitres of gastric content were rapidly aspirated and reintroduced and finally a $3 \mathrm{ml}$ sample was taken to assess the intragastric $\mathrm{pH}$ and this was then returned to the stomach. The $\mathrm{pH}$ was maintained as near to 5.5 as was possible by varying the rate of infusion of bicarbonate. Aspiration of samples and adequate mixing was in our experience much more satisfactory using Oxo than the steak and toast meal of Fordtran and Walsh. Zero time was taken as that time when the instillation of the Oxo meal was complete. In six normal subjects and seven duodenal ulcer patients blood samples were taken for gastrin estimations at times $-5,0,5,10,15,30,45$, and 60 minutes and the plasma separated and stored at $-20^{\circ} \mathrm{C}$ for estimation of plasma gastrin concentration subsequently by radioimmunoassay (Ganguli and Hunter, 1972). The test continued for one hour after introducing Oxo. The integrated plasma gastrin response was calculated as previously described (Ganguli et al., 1974). On a separate occasion after an overnight fast each subject had his maximal acid output determined in response to subcutaneous pentagastrin $6 \mu \mathrm{g} / \mathrm{kg}$ body weight in the conventional manner using a gastric aspiration technique (Multicentre Study, 1969).

The ages of the volunteer subjects, six males and two females, ranged from 20 to 49 years (mean 28.25 years), and in the male duodenal ulcer patients from 27 to 51 years (mean 41.4 years). The average weight of the volunteers was $68.0 \mathrm{~kg}$ and that of the ulcer patients was $\mathbf{7 0 \cdot 2} \mathrm{kg}$.

\section{Results}

The mean cumulative acid outputs in the control and duodenal ulcer subjects are shown in Fig. 1 in mmol per 15 minutes at intervals up to one hour. Throughout the study an increased acid output in response to Oxo was observed compared with that to pentagastrin in normal subjects. The response

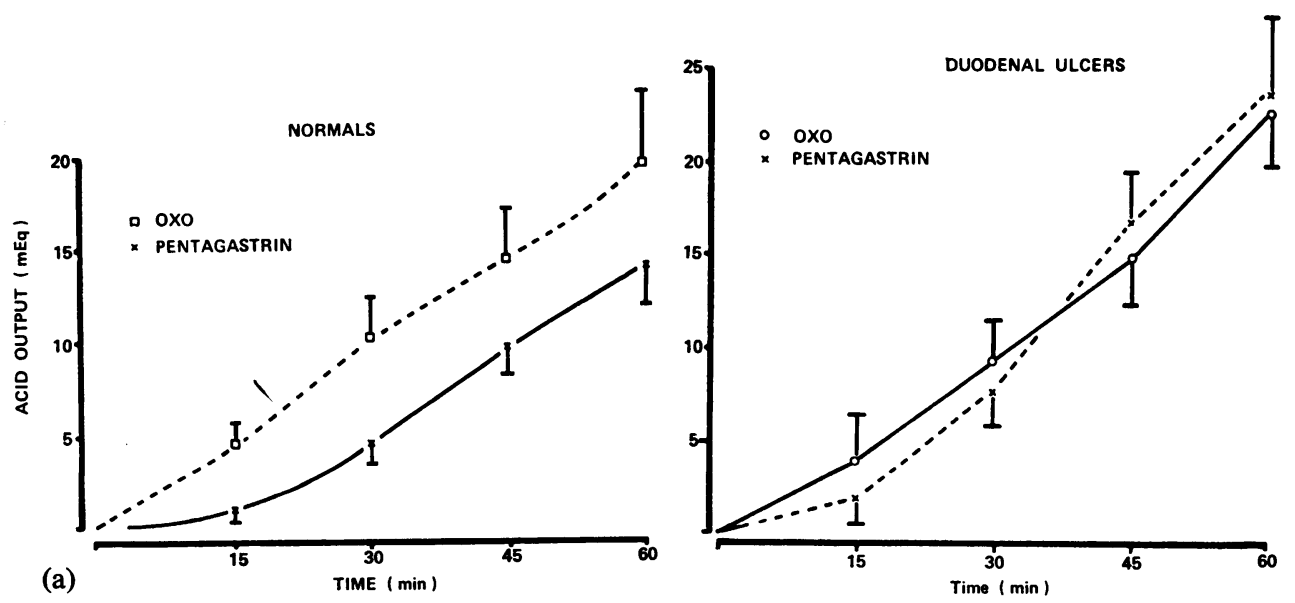

Fig. 1 Cumulative acid outputs to pentagastrin and to Oxo (a) in normal subjects and (b) in duodenal ulcer subjects. A significant difference between the responses to Oxo and pentagastrin was observed in normal subjects only $(\mathrm{P}<0.01)$. Mean $\pm S D(1 \mathrm{mEq}=1 \mathrm{mmol})$. 


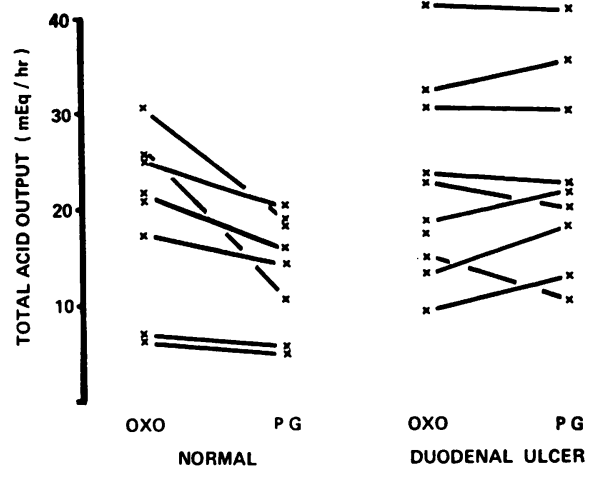

Fig. 2 Total acid output ( $m E q$ per hour) in the two groups of subjects. A significant increase in acid output in response to the Oxo meal was noted only in normal subjects $(\mathrm{P}<0.01)(1 \mathrm{mEq}=1 \mathrm{mmol})$.

to Oxo seemed to start more rapidly in the control group. In marked contrast to the control group data, there was no statistically significant difference in the mean cumulative acid responses to Oxo and to pentagastrin in the duodenal ulcer group (Fig. 1b). The mean total cumulative acid outputs for the duodenal ulcer group to the two stimulants after one hour were within $0.5 \mathrm{mmol}$ of each other.

Total acid output at one hour in individual subjects is shown in Fig. 2. The enhanced secretory response when Oxo was given compared to the response to pentagastrin in normal subjects $(\overline{\mathbf{x}}$ for normal subject to $O x o=20 \cdot 1 \pm 3 \cdot 1(\mathrm{SEM}) \mathrm{mmol} / \mathrm{h}$, $\overline{\mathbf{x}}$ for $\mathrm{Pg}$ acid response $=13.4 \pm 2 \cdot 1$ ) is clearly apparent for each subject, whereas in the duodenal ulcer patients there was no appreciable or consistent difference between the two recordings in the individuals studied nor in the means ( $\overline{\mathrm{x}}$ DUs to Oxo = $23.0 \pm 4.4$ and to $\mathrm{Pg}=22.7 \pm 4.4$ ). The mean percentage $\mathrm{Oxo} / \mathrm{Pg}$ ratio for acid response in normal subjects was $146 \%$ and for duodenal ulcer subjects $98 \%$. The mean percentage difference was $48 \%$ and this was statistically significant $(P<0.025)$. In general there was, however, a good correlation for all the subjects between the acid output to Oxo and that to pentagastrin (Fig. 3).

For those subjects in whom the integrated gastrin response was calculated, comparison with acid output estimated by intragastric titration is shown in Figs. 4a and b. Using Spearman's rho as a non-parametric measure of correlation these trends were not significant.

\section{Discussion}

Liquid meals have been used previously to study gastric functions (Hunt, 1951; Johansson et al., 1972)

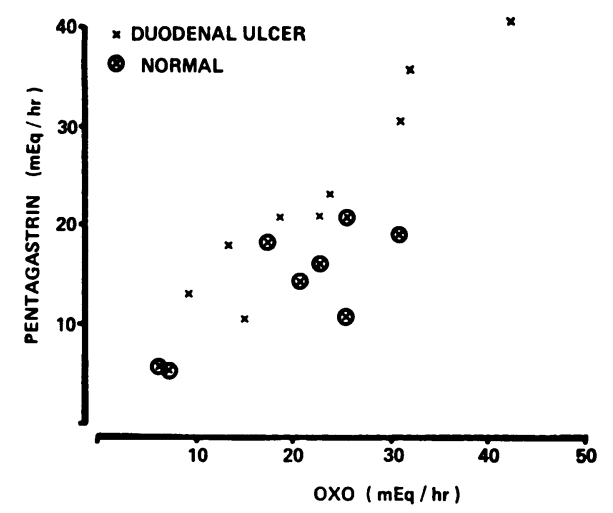

Fig. 3 Overall correlation between acid output Oxo to (by intragastric titration method) and acid output to pentagastrin (conventional nasogastric aspiration) was good. $(R=0.77, \mathrm{P}<0.01)(1 \mathrm{mEq}=1 \mathrm{mmol})$.

and, as with the present method, these studies suffered from the objection that they might not provide the same stimulus as ordinary solid meals, because of their different physical characteristics. Recently Malagelada et al. (1976) described a method for measuring gastric secretion and emptying rates after ingestion of an ordinary solid and liquid meal without the use of manipulation of intragastric pH by titration. Their technique measures the movements of volume across the pylorus by using constant duodenal perfusion with a non-absorbable marker and another marker which is incorporated in the meal. Such a method, however, requires both duodenal intubation and perfusion as well as gastric intubation and, although very elegant, is difficult and somewhat complicated for routine use.

In the present study we have used Fordtran's technique except that we have substituted Oxo for the steak meal.

As the accuracy of the intragastric titration method depends fundamentally upon easy and thorough mixing of gastric contents to secure adequate neutralisation of acid by bicarbonate before appreciable gastric emptying takes place, ease of aspiration and free flow of the 'meal' in the nasogastric tube are desirable. Our test meal, Oxo, was much more easily handled than the steak and toast meal described by Fordtran and Walsh (1973). There are other obvious economic advantages. It is important to maintain the $\mathrm{pH}$ of the intragastric solution as near to 5.5 as is possible throughout the study and it is therefore fortunate that the initial $\mathrm{pH}$ of the Oxo solution is very close to this value. Therefore, if careful control of intra- 


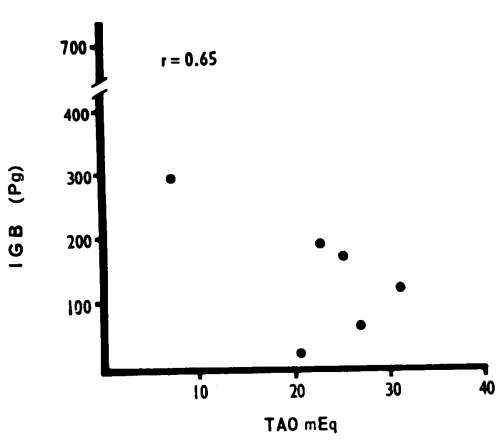

(a)

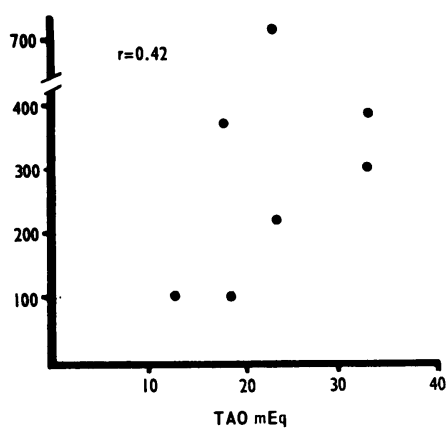

(b) gastric $\mathrm{pH}$ is maintained, the loss of any gastric secretion through the pylorus should already be accounted for by titration with bicarbonate. This rationale however fails to take account of any partial neutralisation by regurgitation of duodenal and small intestinal content.

There is conflicting evidence on the comparative rates of gastric emptying in normal and duodenal ulcer subjects, especially in response to a liquid meal. Several groups of investigators have shown no difference in emptying rates between normal and duodenal ulcer subjects (Hunt, 1957; Brömster et al., 1966; George, 1968), whereas others have found a faster rate of emptying in duodenal ulcer subjects (Kaess and Unger, 1975). Harvey et al. (1970) have suggested that disproportionate gastric emptying of acid or bicarbonate could occur if mixing was inadequate, particularly after partial gastrectomy. Assessment of the present method has not yet been made in postoperative subjects.

The data on changes in serum gastrin concentration relative to acid output after intragastric titration of the Oxo meal are inconclusive, emphasising the lack of correlation between acid output and integrated plasma gastrin response.

Our results in this study are at variance with those of Fordtran and Walsh, and this discrepancy may be either methodological or related to the use of a different stimulus from the intragastric meal. The response to our liquid meal, Oxo, was greater in the normal subjects than the response to pentagastrin, and the response to Oxo in the patients with duodenal ulcer was not less than that to pentagastrin. Inspection of the data suggests that, in the normal group, the observed rates of secretion to each stimulant are different (Fig. 2a), that to Oxo being greater initially, whereas in the duodenal ulcer patients the observed rates of secretion were similar throughout the period of observation. In nine healthy subjects Halter and Keller (1978), using a $500 \mathrm{ml} 10 \%$ meat extract stimulus, also found that the PAO measured by intragastric titration was $35 \%$ greater than that to pentagastrin (6 ug $\mathrm{kg}^{-1}$ ) using conventional aspiration technique. This was similar to our preliminary findings (Elder et al., 1976). Interestingly, Halter and Keller also measured the response to pentagastrin using the intragastric titration method in their normal subjects and found that the mean PAO was not significantly different from that obtained to meat extract. Essentially the differences between conventional aspiration technique and intragastric titration for measuring acid output are that, in the latter, intragastric $\mathrm{pH}$ is maintained at or very near $\mathrm{pH} 5.5$ and acid either newly secreted or neutralised remains in the stomach. Why the acid response measured by intragastric titration is greater both in our study and that of Halter's requires explanation. It is possible that the very different intraluminal $\mathrm{pH}$ conditions obtaining during intragastric titration affect the secretory responsiveness of the parietal cells or it could, in addition, alter the permeability characteristics of the mucosa with regard to acid back diffusion in normal subjects. Both of these hypotheses require further investigation. On the other hand, Fordtran and Walsh suggested that parietal cell responsiveness to a meal in duodenal ulcer subjects is increased giving an enhanced acid output. Isenberg and his colleagues (1975) suggested that patients with duodenal ulceration were hypersensitive to small doses of pentagastrin and this would be in keeping with increased vagal drive in this group. Certainly, studies of pentagastrin dose response curves against a varying background of vagal stimulation have demonstrated experimentally that the acid response to pentagastrin is greatly enhanced by even low levels of vagal background (Passaro and Grossman, 1964; Uvnäs et al., 1966), which suggests that the role of the vagus is to activate the parietal cells so that they may respond more easily to gastrin release produced by food (Emăs and Svensson, 1972). Endogenous stimulation by Oxo in both the normal and duodenal ulcer patients invokes mecha- 
nisms for stimulation of gastric acid secretion such as distension, antral stimulation of G-cells by amino-acids, direct fundic stimulation, and stimulation involving long and short vagal reflex arcs. Only the circumstances of intraluminal stimulation utilise these factors in both normal and duodenal ulcer subjects. If in duodenal ulcer subjects endogenous activation of parietal cells-that is, increased 'vagal tone'-is present in the fasting state, then it is not surprising that stimulation by exogenous pentagastrin in these circumstances has resulted in acid outputs similar to those invoked by the activation and interplay of stimulatory mechanisms produced by the endogenous stimulation of the Oxo meal. In normal subjects heightened endogenous 'vagal tone' is not postulated and one would expect a smaller response to exogenous stimulation by pentagastrin than to the endogenous stimulation by the meat extract, involving as it does the interplay of many stimulating mechanisms in the stomach.

We thank Miss G. Cheetham for help with gastrin assays and Mrs A. Tomlin for technical assistance with the intragastric titration studies. The Department of Medical Illustration, Manchester Royal Infirmary, provided the charts and Mrs M. McNiven and Mrs Carol Gee gave valuable secretarial assistance.

\section{References}

Brömster, D., Carlberger, G., and Lundh, G. (1966). Measurement of gastric emptying rate (Letter). Lancet, 2, 224-225.

Elder, J. B., Ganguli, P. C., and Taylor, T. V. (1976). Comparison of gastric acid outputs measured by an intragastric titration method (Oxo stimulation) with the response to exogenous gastrin pentapeptide in normal subjects. Journal of Physiology, 257, 40-41 P.

Emăs, S., and Svensson, S. O. (1972). Dose-response curves for acid output to histamine and pentagastrin determined by two techniques. Scandinavian Journal of Gastroenterology, 7, 751-757.

Fordtran, J. S., and Walsh, J. H. (1973). Gastric acid secretion rate and buffer content of the stomach after eating. Results in normal subjects and in patients with duodenal ulcer. Journal of Clinical Investigation, 52, 645-657.
Ganguli, P. C., and Hunter, W. M. (1972). Radio-immunoassay of gastrin in human plasma. Journal of Physiology, 220, 499-510.

Ganguli, P. C., Polak, J. M., Pearse, A. G. E., Elder, J B., and Hegarty, M. (1974). Antral-gastrin-cell hyperplasia in peptic ulcer disease. Lancet, 1, 583-586.

George, J. D. (1968). New clinical method for measuring the rate of gastric emptying: the double sampling test meal. Gut, 9, 237-242.

Giles, G. R., and Clark, C. G. (1966). Gastric secretion stimulated by meat extract in man. Scandinavian Journal of Gastroenterology, 1, 159-166.

Halter, F., and Keller, M. (1978). A comparison between intragastric titration and aspiration technique under basal conditions and after food or pentagastrin stimulation. American Journal of Digestive Diseases. (In press).

Harvey, R. F., MacKie, D. B., Brown, N. J. G., Keeling, D. H., and Davies, W. T. (1970). Measurement of gastric emptying time with a gamma camera. Lancet, 1, 16-18.

Hunt, J. N. (1951). The secretory pattern of the stomach of man. Journal of Physiology, 113, 169-184.

Hunt, J. N. (1957). Some notes on the pathogenesis of duodenal ulcer. American Journal of Digestive Diseases 2, 445-453.

Isenberg, J. I., Grossman, M. I., Maxwell, V., and Walsh, J. H. (1975). Increased sensitivity to stimulation of acid secretion by pentagastrin in duodenal ulcer. Journal of Clinical Investigation, 55, 330-337.

Johansson, C., Lagerlöf, H. O. Ekelund, K., Kulsdom, N., Larsson, I., and Nylind, B. (1972). Studies of Gastrointestinal interactions. III. Determination of gastric secretion and evacuation, biliary and pancreatic secretion, intestinal absorption, intestinal transit time and flow of water in man. Scandinavian Journal of Gastroenterology, 7, 489-499.

Kaess, H., and Unger, W. (1975). Evaluation of a new method for the intragastric titration of gastric juice. Acta Hepato-gastroenterology, 22, 242-248.

Malagelada, J. R., Longstreth, G. F., Summerskill, W. H. J., and Go, V. L. W. (1976). Measurement of gastric functions during digestion of ordinary solid meals in man. Gastroen terology, 70, 203-210.

Multicentre Study (1969). Intramuscular pentagastrin compared with other stimuli as tests of gastric secretion. Lancet, 1, 341-343.

Passaro, E. P., Jr, and Grossman, M. I. (1964). Effect of vagal innervation on acid and pepsin response to histamine and gastrin. American Journal of Physiology, 206, 1068-1076.

Rune, S. J. (1966). Comparison of the rates of gastric acid secretion in man after ingestion of food and after maximal stimulation with histamine. Gut, 7, 344-350.

Unväs, B., Emăs, S., Fyrö, B., and Sjodin, L. (1966). The interaction between vagal impulses and gastrin on the control of gastric acid secretion. American Journal of Digestive Diseases, 11, 103-112. 